\title{
Change of the agenesis rate of palmaris longus muscle in an isolated village in Ukraine
}

\author{
N. Barkáts \\ Postgraduate student, Department of Biological Anthropology, Eötvös Loránd University, Budapest, Hungary
}

[Received 3 September 2014; Accepted 3 November 2014]

Background: The palmaris longus muscle (PLM) is a slender, fusiform muscle which lies on the flexor surface of the forearm. Its agenesis is considered the most frequent anatomic variation in the human body. Agenesis of PLM shows strong racial and ethnic variability. The aim of this study was to examine the prevalence of agenesis of PLM in Dercen, an isolated Hungarian village in Ukraine.

Materials and methods: Five hundred forty-eight persons were examined by Thompson's, Shaffer's, Pushpakumar's, Mishra's 1, and Mishra's 2 tests to confirm or refute the presence of a PLM. All the examined subjects were of Hungarian ethnic origin.

Results: The overall prevalence of absence of the palmaris longus was $52.92 \%$. During the examination, unusual results appeared regarding the agenesis of PLM in the elder population of village. Further tests among elder population shoved that in people born before 1945 the agenesis rate of PLM was higher than $70 \%$, and in villagers born after 1945 the agenesis rate drops by $23 \%$.

Conclusions: In the light of historical events of the country, we can say that the unexpected change of the PLM agenesis rate in 1945 was caused by invasion of soviet army and deportation of local men from their homeland. (Folia Morphol 2015; 74, 4: 470-474)

Key words: palmaris longus muscle, tendon, agenesis, isolated population

\section{INTRODUCTION}

Palmaris longus (PL) is often described as one slender and fusiform muscle, with a short muscular belly which is positioned proximally and a long tendon $(10-12 \mathrm{~cm}$ ) which passes anterior (superficial) and distally in forearm of the upper limb of humans and disposes medial to flexor carpi radialis. It is innervated by median nerve and irrigated by branches from anterior ulnar recurrent arteria. This muscle has its origin in the medial epicondyle of the humerus [9]. PL has largely abandoned a direct bony attachment by attaching instead to the palmar fascia [3]. The PL muscle (PLM) is considered to be a phylogenetically degenerated muscle, its function no longer necessary for the proper operation of the human hand. Probably this is one of the main reasons of its great variability and frequent absence, because even without it the human palm can function perfectly. According to studies done to date, the incidence of PLM agenesis is gradually increasing. It is suggested that because this muscle is phylogenetically regressive, the PLM will gradually lose its function totally [4]. However, some studies suggest that the PLM still has a role in certain activities performed by human hand [5].

The PLM is currently one of the most variable muscles in the human body. Among the variations of

Address for correspondence: N. Barkáts, Postgraduate student, Department of Biological Anthropology, Eötvös Loránd University, Pázmány Péter sétány 1/c. (4th floor), 1117 Budapest, Hungary, tel: 0036205480009, e-mail: barkatsn@gmail.com 
PLM we may find duplication of muscle, dislocation of the muscular belly, reversed muscle, and many others; the agenesis is its most frequent anatomical variation $[6,13,14]$. The rate of PLM agenesis varies greatly in different populations. Differences in prevalence of PLM absence in different populations can be observed in the literature dealing with this topic. It is generally accepted that there is a relation between ethnicity and the frequency of PLM agenesis [13], since the agenesis of PLM is inheritable, although till now there are only a few articles dealing with inheritance or with genetic background of the PLM agenesis, just as there are no articles giving any certain information on this topic. However, there are suggestions that presence of PLM might be dominant over its absence $[7,10,17]$.

The prevalence of agenesis of PLM among ethnic Hungarians has been studied in Transcarpathia (Ukraine) [18], and in Slovakia [2]. The absence of PLM is one of the most easily detected anatomic anomalies; therefore there are constant attempts to find out whether its absence shows correlation or association with any other anomaly or abnormality $[1,11]$.

The goal of this study is to examine and evaluate the agenesis rate of the PLM in an isolated village in the Transcarpathia (Ukraine). The villagers are known to lead an isolated and secluded life. Inhabitants of Dercen are of Hungarian ethnic origin, contrary to the Ukrainian majority living in the area. Most of the local families lived in this village for many generations. They have had no contact with the inhabitants of other villages or cities for a long time. Because of factors mentioned above, Dercen presented an interesting ground for a study of an inheritable anatomic anomaly.

The original aim of the study was to estimate the prevalence of agenesis of PLM in this population, but after first tests were carried out and evaluated, a strange tendency shoved in results. The agenesis of PLM was much higher among the elder population then among the general population. This served as a reason for further much more thorough examination of PLM agenesis among the elder population. The analysis of data also showed that the agenesis rate slightly changed in the people who were born after 1991.

\section{MATERIALS AND METHODS}

The examined village Dercen is in Transcarpathia (Ukraine). The population of village is 2793 people, 2727 inhabitants are of Hungarian ethnic origin. Out of the 2727 Hungarian inhabitants, 548 persons were examined. This provides the results with $99 \%$ confidence level, and confidence interval of 5 range.

Parallel with the examination of PL agenesis a demographic research in the mayor's office was carried out. It intended to examine the mobility of people in the village in the past 100 years. This research confirmed that until 1990s villagers led strongly isolated life. Only very few people left the village and even fever came in the village. Most of people who came from other villages were descents of those who left Dercen one or two generations ago. The marriages with people from other villages were extremely rare. Even rarer were the marriages with representatives of other nationalities than Hungarian.

Five hundred forty-eight ethnic Hungarians (245 males and 303 females) of the village Dercen were studied. Of these, 113 were born before 1945 (during the study all the villagers whom were born before 1945 and still lived in the village were examined).

To confirm or refute the presence of a PLM, the following 5 tests were done: Thompson's [16], Shaffer's [15], Pushpakumar's [12], Mishra's 1 [8], Mishra's 2 [8]. For increased accuracy, palpation was performed in every case.

The PLM was considered to be present in the cases where it could be visualized or palpated in at least one of the 5 tests, and it was considered absent when it could not be palpated or visualised in any of the tests.

For the evaluation of results $\chi^{2}$ test vas used in Microsoft Excel 2010 software.

\section{RESULTS}

During the evaluation of tests done in the examined sample, the rate and distribution of agenesis could be divided in three groups according to the age of examined persons. Namely: people who were born before 1945, people born between 1945 and 1991, and people who were born after 1991. The discussion of the results first will give the description of the whole sample, and will continue with the description of each age group separately.

During the examination the following results were acquired for the whole sample: PLM was absent in 290 subjects ( $52.92 \%$ of all examined subjects). Unilateral absence was found in 98 subjects $(17.88 \%$ of all examined subjects); bilateral agenesis was found in 192 subjects (35.03\% of all examined subjects). According to $\chi^{2}$ test, the differences between man 

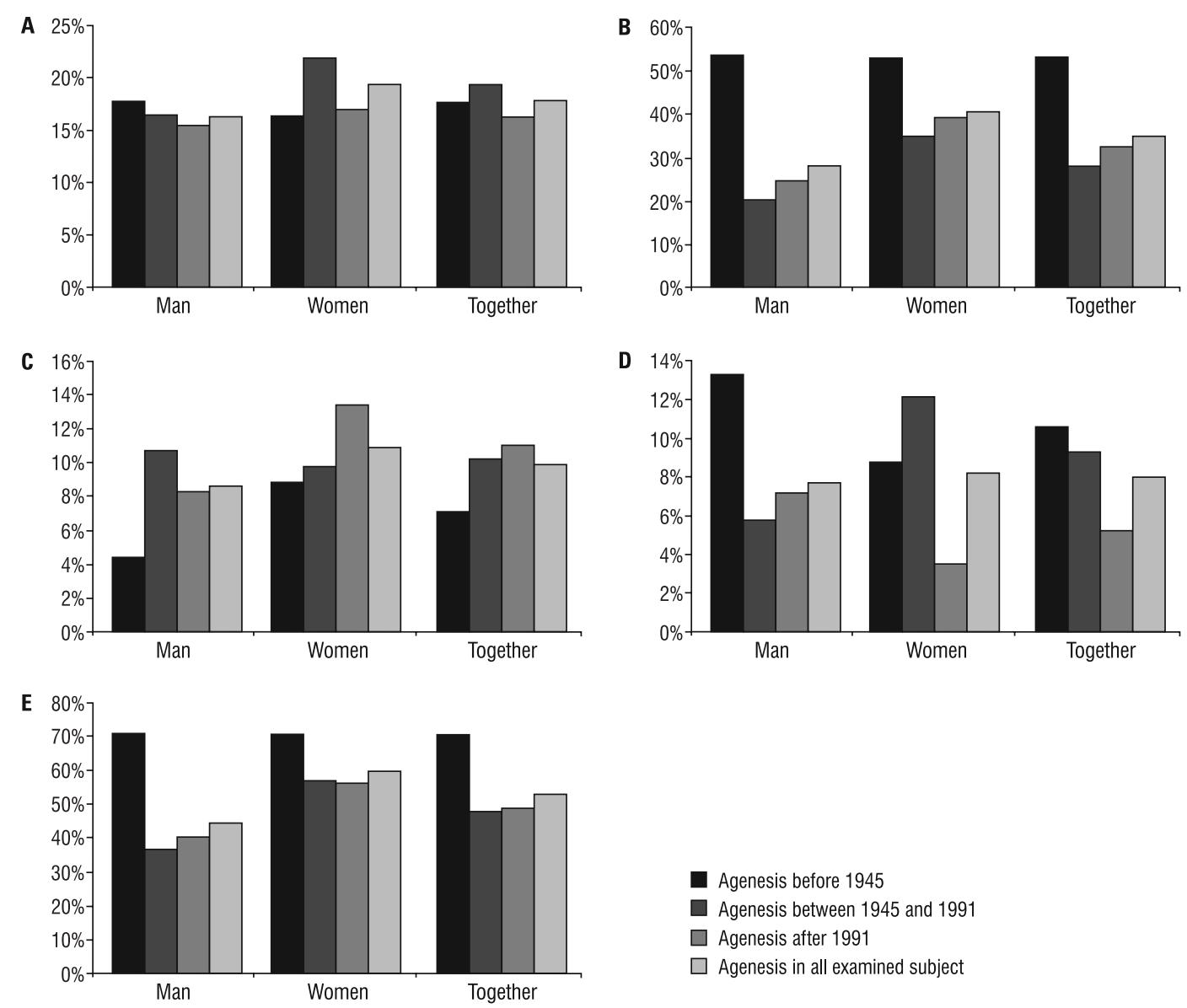

Figure 1. A. Unilateral agenesis in different age groups; B. Bilateral agenesis in different age groups; C. Agenesis in right hand in different age groups; D. Agenesis in left hand in different age groups; E. Agenesis in different age groups in the whole sample.

and women were significant only in the cases of bilateral and overall agenesis. The detailed analysis of distribution of agenesis betveen genders and limb sides (right or left hand), see Figure 1.

As we can see in Figure 1, the agenesis of PLM in the examined population is high in comparison with the agenesis rate of other examined Caucasian populations [2].

The tests performed with the 113 people born before 1945 (all the people in the village, who were born before 1945 were examined during the study) showed the following results: agenesis was found in 80 persons $(70.79 \%$ of all examined subjects), unilateral agenesis was found in 20 persons $(17.70 \%$ of all examined subjects), bilateral agenesis was found in 60 persons (53.09\% of all examined subjects). No significant differences between man and women were found in the people born before 1945. The detailed display of distribution of agenesis between genders and limb sides (right or left hand) (Fig. 1).
Two hundred twenty-six people were examined who were born in the period from 1945 to 1991. In this sample agenesis was found in 108 persons ( $47.79 \%$ of all examined subjects); unilateral agenesis was found in 45 persons (19.47\% of all examined subjects) and bilateral agenesis was found in 64 persons (28.32\% of all examined subjects). In this sample we can see a difference in agenesis rate between man and women. According to $\chi^{2}$ test, the differences between man and women were significant only in the cases of bilateral and overall agenesis (Fig. 1).

After comparing the agenesis rate in the people who were born before 1945 and who were born between 1945 and 1991 (Fig. 1), we can say that the overall agenesis rate is much lower in people who were born between 1945 and 1991 than in people who were born before 1945. Compared with previous sample, the unilateral agenesis increased by $1.77 \%$; yet if we take a separate look at man and women, we can see that in man unilateral agenesis decreased by 
$2.04 \%$ while in women increased by $5.5 \%$. In men, agenesis in right hand increased by $5.74 \%$ which is an increase more than in two times. In women, agenesis in right hand increased by $0.93 \%$. In man, the agenesis in left hand decreased by $7.78 \%$, which is a decrease more than by half. In women, agenesis in left hand increased by $3.38 \%$. Yet according to $\chi^{2}$ test the only case when the changes were significant (both in man and women) was the bilateral agenesis. In man, the bilateral agenesis rate decreased by $34.18 \%$ which is a decrease more than by half ( $p=0.00006)$. In women, the bilateral agenesis decreased by $17.99 \%$ ( $p=0.015)$. The overall agenesis in man decreased by $35.75 \%$ ( $p=0.0001)$, which is a decrease more than by half; in women the overall agenesis decreased by $13.7 \%$ which according to $\chi^{2}$ test wasn't a significant decrease $(p=0.062)$.

Although the agenesis rates in two age groups show great differences, the $\chi^{2}$ test shows that they are significant only in some cases, which is caused by relatively small sample size. Unfortunately, the sample size could not be bigger, since all the people who were born in village before 1945 were examined.

Two hundred and nine people were examined who were born after 1991. In this sample agenesis was found in 102 persons (48.8\% of all examined subjects); unilateral agenesis was found in 34 persons (16.26\% of all examined subjects) and bilateral agenesis was found in 68 (32.53\% of all examined subjects). Significant differences $(p<0.05)$ in the agenesis rate of men and women occur only in the cases of bilateral and overall agenesis. The detailed analysis of distribution of agenesis between genders and limb sides (right or left hand) (Fig. 1).

After comparing the agenesis rate between the people who were born between 1945 and 1991 and those who were born after 1991 (Fig. 1), we can see that compared with the results in previous sample most parameters changed only slightly. The overall rate of unilateral agenesis decreased by $3.21 \%$. In man, unilateral agenesis decreased by $0.27 \%$ while in women by $4.98 \%$. In men, the agenesis in right hand decreased by $1.93 \%$. In women, the agenesis in right hand increased by $3.64 \%$. In man, the agenesis in left hand increased by $1.66 \%$. In women, the agenesis in left hand decreased by $8.62 \%$; according to $\chi^{2}$ test this was the only significant change $(p=0.01)$ compared with previous sample. The bilateral agenesis in man increased by $5.3 \%$; in women the bilateral agenesis increased by $4.33 \%$. The overall agenesis in man increased by $4.84 \%$, whereas in women it decreased by $0.64 \%$.

\section{DISCUSSION}

The PLM has an important role in orthopaedics, plastic and reconstructive surgery. Its superficial location and easy accessibility and the fact that the muscle is fully developed at birth and can be used as tendon donor muscle in any age group, makes it one of the most frequently used donor muscles in surgery. Therefore, all the information about possible variations and frequency of the muscles' prevalence has significance in orthopaedics, plastic, and reconstructive surgery $[16,17]$.

The agenesis of PLM was thoroughly studied in the population of village Dercen (Transcarpathia, Ukraine). The overall agenesis rate of $52.92 \%$ can be considered an unusually high amount in the Caucasian population. The bilateral agenesis was $35.03 \%$, which means that in this population, when dealing with cases where donor tendon is needed for the reconstruction of an injury, the surgeon must be prepared to use alternative tendon donors, as for example the plantaris muscle, or fascia lata.

During the evaluation of the results strange regularities occurred, this resulted in further examination of PLM agenesis in the elderly population of village. The evaluation showed that people born before 1945 had unusually high agenesis rate. After examining all villagers born before 1945, the obtained data showed that in this age group the PL agenesis rate reached $70.79 \%$. In the people born after 1945, we can observe a strong decrease in the agenesis rate of PLM; the agenesis rate decreased by $23 \%$.

A change of this magnitude in the agenesis rate of a population of an isolated village which had almost no connections with outer world could not happen without an outer intervention, which resulted in a high inflow of new genes into the gene pool of the population. According to demographic research done parallel with the study of PLM agenesis, there was no such documented event in 1944-1945, which could cause such change in gene pool and agenesis of PLM in 1945.

To find what could cause such change in the gene pool of the studied population, we have to examine the historic background of the area. During the World War II the Russian (Soviet) army invaded and occupied the territory of Ukraine and in the October of 1944 they occupied Transcarpathia. The only logical 
explanation of extreme change in the agenesis rate of PLM in the population of an isolated village where no significant population migration was detected is the arrival of the soldiers of the invading army to the region, and the deportation of local men from their homelands.

In 1991, after end of Soviet era, the mobility of population increased; this caused a small change in the agenesis of PLM too. But compared with the change we can see in 1945, this change is insignificant.

\section{CONCLUSIONS}

The results obtained in Dercen give a good example of a case when an artificially created gene flow changes the gene pool of an isolated population, with this changing the pattern of an anatomical and anthropological feature which developed in long time and was typical for the given population. The article gives the first proof for the inheritance of the agenesis of PLM on the level of a whole population. It also shows that in certain cases, when we know the background of a studied population, we can us the agenesis rate of PLM as an anthropological and anatomical population marker.

\section{ACKNOWLEDGEMENTS}

I am most grateful to Dr Michael Webb-Peploe, and Prof. Andrew Cope, without whose valuable advices, help and encouragement I would never have started this work. I also want to express gratitude to every person who participated in the research, and without whose help this study couldn't be completed.

\section{REFERENCES}

1. Agarwal $P$ (2010) Absence of the palmaris longus tendon in Indian population. Indian J Orthop, 44: 212-215.

2. Barkáts N, Nagy M (2013) Agenesis of palmaris longus muscle in representatives of Hungarian population of Slovakia. Science Education New Dimension, 2: 184-187.
3. Benjamin M, Kaiser E, Milz S (2008) Structure-function relationships in tendons: a review. J Anat,212: 211-228.

4. Ceyhan O, Mavt A (1997) Distribution of agenesis of Palmaris longus muscle in 12 to 18 years old age groups. Indian J Med Sci, 51: 156-160.

5. Gangata $H(2009)$ The clinical surface anatomy anomalies of the palmaris longus muscle in the Black African population of Zimbabwe and a proposed new testing technique. Clin Anat, 22: 230-235.

6. Gray H, Goss CM (1973) Anatomy of the human body. 29th Ed. Lea \& Febiger, Philadelphia.

7. Karimi-Jashni H, Rahmanian K, Jahromi AS (2014) Agenesis of palmaris longus in Southern of Iran: A population based study. OnLine J Biol Sci, 14: 8-11.

8. Mishra S (2001) Alternative tests in demonstrating the presence of palmaris longus. Indian J Plast Surg, 34: 12.

9. Moore Kl, Dalley AF (2007) Anatomia Orientada para Clínica. Guanabara Koogan, Rio de Janeiro.

10. Morais MA, Santos WG, Malysz T (2013) Agenesis of palmaris longus muscle: is this a phenotype of variable expressivity? J Morphol Sci, 30: 249-253.

11. O'Sullivan E, Mitchell BS (2002) Association of the absence of palmaris longus tendon with an anomalous superficial palmar arch in the human hand. J Anat, 201: 405-408.

12. Pushpakumar SB, Hanson RP, Carroll S (2004) The 'two finger' sign. Clinical examination of palmaris longus (PL) tendon. Br J Plast Surg, 57: 184-185.

13. Reimann AF, Daseler EH, Anson BJ, Beaton LE (1944) The palmaris longus muscle and tendon. A study of 1600 extremities. Anat Rec, 89: 495-505.

14. Salgado G, Cantin M, Inzunza O, Munoz A, Saez J, Macuer M (2011) Bilateral reversed palmaris longus muscle: a rare anatomical variation. Folia Morphol, 71: 52-55.

15. Schaeffer JP (1909) On the variations of the palmaris longus muscle. Anat Rec, 3: 275-278.

16. Thompson JW, Mc Batts J, Danforth CH (1921) Hereditary and racial variations in the musculus palmaris longus. Am J Phys Anthrop, 4: 205-220.

17. Wehbe MA (1992) Tendon graft donor sites. J Hand Surg Am, 17: 1130-1132.

18. Barkáts N (2012) Agenesis of palmaris longus muscle in the population of Dercen (Transcarpathian region) [in Ukrainian language]. Journal of Cherkasy National University of Bohdan Khmelnytsky. Series: Biological Science, 2: 18-24. 